\title{
The Effects of Acute Nicotine, Chronic Nicotine, and Withdrawal From Chronic Nicotine on Performance of a Cued Appetitive Response
}

\author{
Prescott T. Leach, Kristy A. Cordero, and Thomas J. Gould \\ Department of Psychology, Neuroscience Program, Temple University.
}

\section{Abstract}

Nicotine is a widely used addictive drug, with an estimated 73 million Americans 12 years of age or older having used a tobacco product in the last month, despite documented risks to personal health. Nicotine alters cognitive processes, which include effects on attention and impulsivity, a mechanism that may contribute to the addictive properties of the drug. Individuals with a variety of psychological disorders ranging from attention deficit hyperactivity disorder (ADHD) to schizophrenia smoke at a higher rate than the rest of the population and show deficits in impulse control. The present studies evaluated the effects of acute, chronic, and withdrawal from chronic nicotine on an operant task that measured premature and signaled nose pokes, as well as performance efficiency in C57BL/6J mice. Results indicate that acute nicotine $(0.09 \mathrm{mg} / \mathrm{kg}$ intraperitoneally) does not alter the acquisition of the task, but does significantly increase performance efficiency once the behavior has been learned. In contrast, chronic nicotine $(0,6.3$, 12.6 , and $36 \mathrm{mg} / \mathrm{kg} /$ day subcutaneously) and withdrawal from chronic nicotine had no effect on performance efficiency. These results suggest that initial nicotine use may have beneficial effects on inhibitory control, but these effects are not maintained with chronic nicotine consumption as tolerance develops. The findings may provide an explanation for higher rates of smoking in patients with impulse control issues, as the smoking may represent an initial attempt at selfmedication.

\section{Keywords}

learning; acetylcholine; addiction; impulsivity; ADHD

Cigarettes are commonly used, with as many as $25 \%$ of $18-44$ year olds in the United States being current smokers (Glynn, Cryan, Kent, Flynn, \& Kennedy, 2009). Overall, smoking rates have been declining, yet it is still the leading cause of preventable death in the United States (Glynn et al., 2009). Education as to the risk of cigarette smoking and successful legislation banning smoking in bars and restaurants have aimed to reduce smoking rates (Callinan, Clarke, Doherty, \& Kelleher, 2010), but declines appear to be leveling off. Recent 
estimates indicate 73 million Americans over the age of 12 have used a tobacco product in the last month (National Survey on Drug Use \& Health; Barker et al., 2010) despite their adverse effects on health (Ockene \& Miller, 1997; Swan \& Lessov-Schlaggar, 2007). Nicotine is the main addictive component of cigarettes (Le Foll \& Goldberg, 2009; De Biasi \& Dani, 2011), yet nicotine has relatively low reinforcing properties as compared with other common drugs of abuse (Henningfield \& Goldberg, 1983; Le Foll \& Goldberg, 2009). Other factors, in addition to the reinforcing properties of nicotine, may exist that contribute to the high rates of tobacco use and one factor may be comorbid disorders.

Many neuropsychiatric disorders share comorbidity with cigarette smoking and nicotine dependence, including schizophrenia, bipolar disorder, post traumatic stress disorder (PTSD), and attention deficit hyperactivity disorder (ADHD; Leonard et al., 2001). One underlying trait many of these disorders share is impulsive behavior. For instance, subjects with schizophrenia have deficits in conscious inhibitory processing, as compared with control subjects (Huddy et al., 2009). Bipolar patients exhibit elevated levels of impulsivity (Strakowski et al., 2010), which correlates with a decreased quality of life (Victor, Johnson, $\&$ Gotlib, 2011). In addition, impulsive behaviors are associated with substance use in subjects with PTSD (Weiss, Tull, Viana, Anetis, \& Gratz, 2012). Childhood and adolescent ADHD may confer higher risk for the initiation of cigarette smoking (Milberger, Biederman, Faraone, Chen, \& Jones, 1997), and later development of substance use disorders, including nicotine dependence (Elkins, McGue, \& Iacono, 2007). As a potential consequence, rates of smoking in subjects with ADHD are higher than the general population (Pomerleau, Downey, Stilson, \& Pomerleau, 1995).

The different effects of acute, chronic, and withdrawal from chronic nicotine on attention and impulsivity may contribute to the initiation and maintenance of smoking and may decrease the likelihood of a successful quit attempt in subjects with impulse control problems. Two recent studies using self-report questionnaires showed that the presence of ADHD-like symptoms prior to a quit attempt (hyperactivity/impulsivity and inattention) predict difficulty in quitting smoking (Covey, Manubay, Jiang, Nortick, \& Palumbo, 2008) and that smoking cessation increases hyperactivity/impulsivity symptoms (Rukstalis, Jepson, Patterson, \& Lerman, 2005). Both of the aforementioned studies found that hyperactivity/impulsivity symptoms were more predictive of difficulty quitting. The present study sought to determine if there were differential effects of acute, chronic, and withdrawal from chronic nicotine on an appetitive signaled nose poke task that measures response inhibition. The C57BL/6 inbred strain of mice was used, as they were shown to exhibit moderate levels of impulsive-like behaviors in this task (Logue, Swartz, \& Wehner, 1998). Understanding the distinct effects of acute, chronic, and withdrawal from chronic nicotine on cognitive processes will help the development of more targeted strategies for preventing the initiation of smoking and/or enhancing the success of smoking cessation therapies, especially in patient populations with impulse control issues.

\section{Methods}

For all experiments, male C57BL/6J mice (Jackson Laboratories, Bar Harbor, ME), 8-9 weeks old at the start of training, were acclimated to a temperature- and humidity-controlled 
vivarium for 1 week with ad libitum access to standard lab chow and water. After the acclimation period, mice were single housed, weighed, and started on 1 week of food restriction, after which they were maintained at $85 \%$ of their free fed weight for the entire course of behavioral experimentation. During the initial food restriction period, mice were given daily access to purified precision pellets made by Bio-Serv Inc (Frenchtown, NJ) in order to acclimate them to the novel food.

Training occurred in modular Med-Associates (St Albans, VT) mouse operant chambers (18 $\times 19 \times 38 \mathrm{~cm}$ ), each equipped with a house light, food magazine, and $25 \mathrm{mg}$ pellet dispenser, two infrared fitted nose poke holes on either side of the food magazine, and white noise generator, controlled by Med-PC IV software. Original operant programs were written by Sheree Logue, PhD (Logue et al., 1998) and were subsequently modified by Prescott Leach.

Operant conditioning began with Phase 1, a continuous reinforcement (CRF) protocol. During this protocol, mice were pseudorandomly assigned to left or right reinforced groups, where reinforcement (1 reward pellet) was given for nose pokes in the assigned spatial location (e.g., left group in left nose poke hole). Nose pokes in the nonreinforced side were counted, but had no consequences (i.e., punishment or reward). After 25 rewards in a single session, subjects moved on to Phase 2 of training, which consisted of a fixed ratio-3 (FR-3) protocol. Each mouse received the same reinforced nose-poke hole (left or right) as during CRF training, but the schedule of reinforcement was increased to require three responses to obtain a reward. Mice remained on FR-3 training until 25 responses were made during one 30-min session.

A schematic is provided (see Figure 1) that describes the key parts of the appetitive signaled nose-poke task. Phase 3 of training maintained right/left rewarded nose-poke holes from previous phases; however, reward was only delivered if correct nose pokes occurred during a conditioned stimulus (conditional stimulus [CS]) presentation consisting of a 3-s, 85-dB white noise. Each trial began with a 30-s intertrial interval (ITI) immediately followed by an unsignaled variable interval (VI, 1-8 s), followed by the CS. Nose pokes on either side during the ITI had no consequences (i.e., punishment or reward). Nose pokes on the correct side during the VI (i.e., prior to stimulus presentation) restarted the interval. The VI period restarted upon each successive nose poke that occurred within the VI until responses were successfully withheld for the entire period (i.e., inhibition of prepotent responses). When the VI period elapsed and the CS was presented, nose pokes on the correct side during the CS were rewarded, and the CS was terminated. If no response was made during the CS presentation, a new 30-s ITI began and no response was recorded. Mice received Phase 3 training until 10 reinforcers were received in one 30-min session. During this phase, all correct and incorrect nose pokes were recorded during each individual portion of the task.

Phase 4 of training was identical to Phase 3, but the ITI was reduced to $20 \mathrm{~s}$. Phase 4 testing was used to assess acquisition of the task under low attentional load. Phase 5 was identical to Phase 4, except the CS was shortened to $2 \mathrm{~s}$. This reduced performance slightly to allow for a bigger "window" for pharmacological enhancement of responding after performance criterion was reached. 
During Phases 3, 4, and 5, calculations were performed for percent conditioned reinforcers (\% CRs) and efficiency ratio (ER). Percent CRs were calculated as the number of rewards earned divided by the number of CS presentations $\times 100$. The $\%$ CRs can be used as a measure of participation (i.e., higher \% CRs indicate successful participation in the task). The ER was calculated as the number of rewards earned divided by the total number of rewarded and nonrewarded nose pokes. The ER performance has been used to measure performance efficiency, which has been interpreted as a measure of impulsive action (i.e., multiple nonrewarded nose pokes indicate higher impulsive action; Logue et al., 1998). This task was chosen for its high degree of translatability to humans (Mitchell, 2004). Standard Go/No-go tasks like the one used here are readily administered in humans (Finn, Justus, Mazas, \& Steinmetz, 1999). In addition, variations of this task have successfully been used to evaluate performance efficiency in rats (Steinmetz, Logue, \& Miller, 1993; Banks, Mohr, Besheer, Steinmetz, \& Garraghty, 1999; Banks et al., 2001). Furthermore, this task was used to identify differences in performance in a $7 \mathrm{nAChR}$ null mice and heterozygous reeler mice that were attributed to changes in impulsivity and inhibitory control (Keller, Keller, Bowers, \& Wehner, 2005; Krueger et al., 2006).

\section{Drug Preparation and Administration}

Nicotine hydrogen tartrate (Sigma) was dissolved in physiological saline for all experiments. Drug doses were calculated by body weight and are indicated in $\mathrm{mg} / \mathrm{kg}$ (acute) or $\mathrm{mg} / \mathrm{kg} / \mathrm{day}$ (chronic), and are reported as freebase drug concentrations. Acute nicotine $(0$ or $0.09 \mathrm{mg} / \mathrm{kg}$, intraperitoneally ([ip]) was administered at a dose volume of $10 \mathrm{ml} / \mathrm{kg} 5 \mathrm{~min}$ prior to the initiation of the test session based on a dose found to produce plasma nicotine levels similar to those of human smokers (Davis, James, Siegel, \& Gould, 2005). Chronic nicotine (0, 6.3, 12.6 , or $36 \mathrm{mg} / \mathrm{kg} /$ day, subcutaneously [sc]) administration occurred via an osmotic minipump (Model \#1002 Alzet, Inc., Cupertino, CA) that delivered $0.25 \mu \mathrm{l} /$ hour and held a total of $100 \mu \mathrm{l}$ of liquid. Initial dose $(6.3 \mathrm{mg} / \mathrm{kg} / \mathrm{day} \mathrm{sc})$ tested was based on previous research indicating plasma nicotine levels comparable to those produced by acute nicotine $(0.09 \mathrm{mg} / \mathrm{kg})$ and levels observed in human smokers (Davis et al., 2005). Pumps were implanted (as described below), and were removed after 12 days of continuous drug treatment for withdrawal experiments.

\section{Osmotic Mini-Pump Surgeries}

Mice were anesthetized with isoflurane (5\% induction, $2.5 \%$ maintenance) and placed on a stereotaxic instrument for pump implantation and removal surgeries. Osmotic minipumps filled with either nicotine or saline were subcutaneously (sc) inserted or removed from the intrascapular region of the mice using aseptic surgical techniques.

\section{Experiment 1: Evaluation of the Effects of Acute Nicotine on Performance Efficiency}

Experiment 1 determined the specific effects of acute nicotine on performance efficiency. First, the effect of nicotine was evaluated on the acquisition of the operant appetitive signaled nose-poke task (Experiment 1A). Acute nicotine ( 0 or $0.09 \mathrm{mg} / \mathrm{kg}$ ip, once daily [QD]) was administered 5 min prior to the start of testing sessions for each of the 10 days of Phase 4 testing ( $n=7-8$ per group). Next, the effect of nicotine on performance efficiency 
was evaluated in separate mice after performance criterion was reached in the appetitive signaled nose-poke task (Experiment 1B). For Experiment 1B, nicotine (0 or $0.09 \mathrm{mg} / \mathrm{kg}$, ip, QD) was administered 5 min prior to the start of testing sessions for each of the 5 days on Phase 5 ( $n=12-13$ per group). Asymptotic performance was defined as receiving $>80 \%$ conditioned reinforcers for 3 days of Phase 4 (mean $[M]=15.54$ days, standard deviation $[S D]=5.89$ days). The last 2 days of Phase 4 testing were used to establish a baseline level of performance that were then used to sort animals into treatment groups that were equated on baseline efficiency ratio performance ( $M \mathrm{~s}$ and standard error of the mean [SEM] $=0.65 \pm$ 0.04 and $0.64 \pm 0.05$ prior to saline and nicotine administration, respectively). An additional level of analysis was added to Experiment 1B to determine if baseline performance efficiency significantly affected response to nicotine. A median split was performed on baseline ER scores for nicotine treated group. Subsequently, paired $t$ tests were performed comparing baseline ER scores to ER scores during drug administration (average of 5 days) for baseline low ER and baseline high ER. To determine the relationship between the efficiency ratio measure and its constituent values, supplementary tables have been provided with comparisons of ER, rewards, total active responses, and ITI responses.

\section{Experiment 2: Effect of Chronic Nicotine on Performance Efficiency}

Experiment 2 sought to determine if chronic nicotine decreased performance efficiency or if tolerance developed to nicotine's effects. To assess this, mice were trained to Phase 4, as described previously for Experiment 1A. Subsequently, mice were tested for 10 days on Phase 4 prior to being implanted with osmotic minipumps that delivered nicotine $(0,6.3$, 12.6 or $36 \mathrm{mg} / \mathrm{kg} / \mathrm{day} \mathrm{sc}$ ) continuously for a maximum of 14 days ( $n=7-13$ per group). The starting chronic dose of nicotine $(6.3 \mathrm{mg} / \mathrm{kg} /$ day $)$ produces the same plasma nicotine levels as acute nicotine $(0.09 \mathrm{mg} / \mathrm{kg})$ and as seen in smokers (Davis et al., 2005). Mice received 12 days of chronic nicotine and were tested for 10 days during drug administration.

\section{Experiment 3: Effect of Withdrawal From Chronic Nicotine on Performance Efficiency}

Experiment 3 was designed to evaluate the effects of withdrawal from chronic nicotine on performance efficiency in the appetitive signaled nose-poke task. After 12 days of chronic nicotine administration as described in Experiment 2 (0,6.3, 12.6 or $36 \mathrm{mg} / \mathrm{kg} / \mathrm{day} \mathrm{sc})$, osmotic minipumps were removed to induce a spontaneous withdrawal syndrome. Mice were tested for an additional 10 days in Phase 4 of the appetitive signaled nose-poke task beginning $24 \mathrm{hr}$ after pump removal ( $n=7-13$ per group). A follow-up experiment tested shorter nicotine withdrawal ( 0 or $6.3 \mathrm{mg} / \mathrm{kg} /$ day sc) time points $(3,6,12,24$, or $48 \mathrm{hr}$ ) to rule out early/transient withdrawal effects ( $n=6$ per group). The $6.3 \mathrm{mg} / \mathrm{kg} / \mathrm{day}$ dose was chosen because prior studies found withdrawal deficits with this dose in contextual fear conditioning (Davis et al., 2005), trace fear conditioning (Raybuck \& Gould, 2009), and spatial object recognition (Kenney, Adoff, Wilkinson, \& Gould, 2011).

\section{Statistical Analysis}

Statistical analyses included repeated-measures analyses of variance (ANOVAs) with drug treatment as a between-subjects factor and day as the repeated measure. Analyses were conducted for ER, \% CRs/rewards earned, premature nose pokes on the "active" side, and 
total ITI responses during each stage of testing (i.e., acute, chronic, and withdrawal from chronic nicotine), for all experiments. Significant ANOVA results were followed up with simple main effects tests for pair-wise comparisons in the event of differences between treatment groups or linear trend analyses in the event of significant repeated-measures findings. In general, treatment group effects indicate an effect of nicotine administration and repeated-measures effects indicate improvement over time. For graphical representation only, figures are represented as percent vehicle to better illustrate dose responses where each of the doses of nicotine were run with their own vehicle group.

\section{Results}

\section{Experiment 1: Effects of Acute Nicotine on Task Acquisition and Performance Efficiency}

To determine the effect of nicotine on the acquisition of the operant task, acute nicotine was administered to a cohort of drug-naïve animals during the first 10 days of the task (acquisition). Daily ER scores, \% CRs, and group sizes are found in Supplemental Table 1. ANOVA analysis on ER performance revealed no effect of treatment, a significant main effect of day, $F(9,13)=8.102, p<.0001$, and no interaction (see Figure 2). ANOVA analysis on percentage CRs earned revealed no effect of treatment, a significant effect of day, $F(9,13)=6.946, p<.01$, and no interaction. Post hoc analyses revealed significant positive linear trends for both ER and CRs, $F(1,13)=17.985, p<.01$ and $F(1,13)=$ $16.686, p<.001$, respectively. Both groups significantly improved their performance over time, regardless of drug treatment. Analysis of the constituent values of the ER revealed a significant effect of day on premature "active" responses and total ITI responses, $F(1,13)=$ $2.84, p<.05$ and $F(1,13)=3.47, p<.05$, respectively.

To determine the effect of nicotine on performance after reaching a preset criterion in the appetitive signaled nose-poke task, acute nicotine $(0.09 \mathrm{mg} / \mathrm{kg}$ ip) was administered to a cohort of drug naïve mice previously trained to a performance criterion ( 3 days completing $80 \%$ of possible trials). A mixed-model between-within ANOVA revealed a main effect of drug treatment on ER performance, $F(1,23)=4.65, p<.05$, no effect of day, and no interaction. Nicotine-treated animals had a higher ER than vehicle-treated animals over the course of 5 days (see Figure 3). ANOVA analysis revealed no main effect of drug treatment on $\%$ CRs, a significant effect of day, $F(4,23)=3.14, p<.05$, and no interaction. The absence of any drug effect on CRs indicates no suppression of motivation or appetite that would interfere with ER measures. Analysis of the constituent values (Supplemental Table 1) of the ER revealed a significant effect of drug on premature "active" responses, but not on total ITI responses, $F(1,23)=7.16, p<.05$ and $F(1,23)=3.47, p>.05$, respectively.

To take into account baseline ER performance, median splits were performed for the nicotine group, based on ER scores prior to drug administration. Baseline ER scores, as compared with ER scores during drug administration, led to no significant effect of nicotine treatment in high-ER animals, $t(5)=0.7414, p>.05$, but a significant effect of nicotine in low-ER animals, $t(6)=3.251, p<.05$, an effect that is maintained after Bonferroni correction for multiple comparisons. Nicotine selectively enhanced ER performance in mice that exhibited low baseline performance, but had no significant effect on those with high baseline performance. The selective effects of nicotine support the idea that nicotine may be 
used to self-medicate in individuals with performance deficits in inhibitory control tasks (Potter \& Newhouse, 2004).

\section{Experiment 2: Effects of Chronic Nicotine on Performance Efficiency}

To determine the effect of chronic nicotine on performance efficiency, chronic nicotine $(0$, $6.3,12.6$, or $36 \mathrm{mg} / \mathrm{kg} / \mathrm{day} \mathrm{sc}$ ) was administered to mice, and performance was evaluated for 10 days during treatment. The mice used to evaluate the effect of chronic nicotine ( 6.3 and $12.6 \mathrm{mg} / \mathrm{kg} / \mathrm{day} \mathrm{sc})$ were previously exposed to acute nicotine $(0.09 \mathrm{mg} / \mathrm{kg}$ ip) for 5 or 10 days respectively during Experiment 1; saline-treated mice in these experiments had previously received acute saline injections for 5 or 10 days during Experiment 1 . The mice used to evaluate the effect of $36 \mathrm{mg} / \mathrm{kg} /$ day subcutaneous chronic nicotine were drug naïve prior to testing. ANOVA analyses on ER performance revealed no effects of any treatment, significant main effects of day (12.6, and $36 \mathrm{mg} / \mathrm{kg} /$ day $), F(9,13)=4.627, p<.01$; and $F(9$, $23)=3.67, p<.01$, respectively, and no interactions (see Figure 4). Analysis of the constituent values of the ER revealed no significant effect of day, drug, or interaction on premature "active" responses or total ITI responses (Supplemental Table 2).

ANOVA analyses on \% CRs earned revealed no effects of any treatment, significant main effects of day, $F(9,13)=7.59, p<.01$; and $F(9,21)=17.02, p<.0001$ for 12.6, and 36 $\mathrm{mg} / \mathrm{kg} /$ day respectively, and no interactions. Chronic nicotine administration $(6.3,12.6$, or $36 \mathrm{mg} / \mathrm{kg} /$ day sc) had no effect on measures of efficiency ratio performance. These data indicate that the effects of nicotine in this appetitive task disappear with chronic treatment, presumably due to tolerance.

\section{Experiment 3: Effects of Withdrawal From Chronic Nicotine on Performance Efficiency}

To determine the effect of withdrawal from chronic nicotine on ER performance, chronic nicotine $(0,6.3,12.6$, or $36 \mathrm{mg} / \mathrm{kg} /$ day sc) was administered to mice for 12 days, then pumps were removed, and performance was evaluated during spontaneous withdrawal starting 24 $\mathrm{hr}$ after cessation of treatment. ANOVA analyses on ER performance revealed no effects of any treatment, day, and no interactions (Figure 5a). Results of the follow-up study, designed to determine if there were transient withdrawal deficits observed after withdrawal from chronic nicotine ( 0 or $6.3 \mathrm{mg} / \mathrm{kg} / \mathrm{day} \mathrm{sc}$ ), found no effect of treatment or hour, and no interactions (Figure 5b).

ANOVA analyses on \% CRs earned revealed no effects of any treatment, significant main effects of day $(6.3 \mathrm{mg} / \mathrm{kg} /$ day $), F(9,23)=2.09, p=.03$, and an interaction $(6.3 \mathrm{mg} / \mathrm{kg} / \mathrm{day})$, $F(9,207)=1.93, p=.05$. Post hoc analyses revealed that withdrawal from chronic nicotine administration at no dose $(6.3,12.6$, or $36 \mathrm{mg} / \mathrm{kg} / \mathrm{day} \mathrm{sc})$ had a significant effect on measures of performance efficiency. Results of the follow-up study to determine if there were transient withdrawal-related deficits in ER performance starting $3 \mathrm{hr}$ after cessation of treatment found no effect of treatment cessation, a significant effect of hour, $F(4,10)=$ $43.05, p<.01$, and no interaction. Post hoc analysis revealed a significant negative linear trend, $F(4,10)=99.486, p<.0001$, presumably driven by satiation after 4 sessions in a 24$\mathrm{hr}$ period. These data suggest that withdrawal from chronic nicotine does not affect performance efficiency. Analysis of the constituent values of the ER revealed no significant 
effect of day, drug, or interaction on premature "active" responses or total ITI responses (Supplemental Table 3).

\section{Discussion}

The present study found that the effects of nicotine on performance efficiency in an appetitive signaled nose-poke task in C57BL/6 mice changed with treatment duration. Acute nicotine increased performance efficiency in this task once it had been acquired, but did not alter acquisition of the task. This effect was largely driven by subjects with lower baseline performance. Chronic nicotine and withdrawal from chronic nicotine did not affect performance efficiency of the task. Additionally, no treatment affected motivation, as measured by the number of CRs earned. The present findings indicate that acute nicotine can increase the efficiency with which mice perform an appetitive task, but tolerance develops to these effects with chronic nicotine administration. Further, upon evaluation of the constitutive components of the efficiency measure, acute nicotine reduced premature "active" responses, but chronic nicotine had no effect.

The results of the present study are similar to those from studies examining different attention and cognitive tasks that found nicotine decreased premature responding in mice (Pattij et al., 2007), rats (Hahn, Shoaib, \& Stolerman, 2002b; Hahn, Sharples, Wonnacott, Shoaib, \& Stolerman, 2003), and humans (Potter \& Newhouse, 2004). These effects, however, have not been observed in all studies (see Grottick \& Higgins, 2000; Hahn, Shoaib, \& Stolerman, 2002a; Young et al., 2004; Day et al., 2007). It is possible that differences in task parameters and age of the subjects contributed to differences in the effects of nicotine across these studies.

In contrast to studies on acute nicotine, fewer studies have evaluated the effect of chronic nicotine and nicotine withdrawal on inhibitory control. The current study found no effect of chronic nicotine or withdrawal from chronic nicotine on premature responding. However, Shoaib and Bizarro (2005) demonstrated lower premature responses in the 5-CSRTT that started at baseline in the nicotine group and continued to immediately after chronic nicotine treatment ceased, and Semenova, Stolerman, and Markou (2007) showed an increase in premature responses limited to Day 1 of chronic nicotine and a decrease in premature responses limited to Day 3 of withdrawal from chronic nicotine in the same task. Clearly, further work is needed to understand what factors influence chronic nicotine effects on inhibitory control.

In patient populations with deficits in inhibitory control and increased impulsivity, the acute effects of nicotine may be beneficial in the short term by reducing behaviors occurring at inappropriate times. The results of the current study support this by demonstrating that the nicotine enhancement of efficiency was associated with low baseline performance. The results of the chronic and withdrawal from chronic nicotine portions of the current study indicate that these beneficial effects of nicotine may be transient, meaning they would not be maintained with prolonged use. Thus, if individuals with impulse control issues initiate tobacco use in an attempt to self-medicate, they may become addicted with no long-term benefits to their symptomology. Research demonstrates that successful treatment of ADHD 
symptoms in childhood reduces the risk of cigarette smoking during adolescence (Wilens et al., 2008). In other words, when ADHD symptoms are kept under control, the need for selfmedicating with cigarettes may be reduced. Furthermore, the presence of ADHD-like symptoms in those that do not suffer from ADHD may also make it harder to quit smoking (Humfleet et al., 2005; Covey et al., 2008), providing further evidence of a link between impulse control issues and nicotine use.

Impulsive individuals have a harder time abstaining from tobacco use than those without symptoms of impulsivity (Rukstalis et al., 2005; Covey et al., 2008). This relationship could be due to a link between impulsivity and risk of initiation of tobacco use (Fuemmeler, Kollins, \& McClernon, 2007) and/or nicotine withdrawal effects on impulsivity. The current study found no association between nicotine withdrawal and changes in performance efficiency. This is in contrast to the established disruptive effects of nicotine abstinence on other cognitive symptoms in subjects with ADHD (Pomerleau et al., 2003; McClernon et al., 2011). However, our results suggest that nicotine withdrawal does not have a carte blanche effect on all cognitive tasks, but instead affects select cognitive processes. Thus, the use of tobacco products may start as an attempt to manage cognitive symptoms, but continued use may result in tolerance and potentially exacerbate other symptoms.

Adults with ADHD who smoke cigarettes may benefit from pharmacological therapies designed to reduce their impulsivity symptoms and treat cognitive withdrawal symptoms. Stimulant treatment, however, actually increases cigarette smoking in adult smokers with ADHD (Vansickel, Stoops, Glaser, Poole, \& Rush, 2011). This suggests nonstimulant treatment of ADHD symptoms in patients that are smokers may be more effective in also managing nicotine addiction. Atomoxetine is a norepinephrinereuptake inhibitor approved by the U. S. Food and Drug Administration to treat ADHD (Kratochvil, Vaughan, Harrington, \& Burke, 2003). In rats, atomoxetine treatment increased percent correct performance and decreasing premature responses in the 5-CSRTT, whereas methylphenidate had little beneficial effect (Navarra et al., 2008) and in mice, atomoxetine reduced cognitive deficits associated with nicotine withdrawal (Davis \& Gould, 2007). While atomoxetine does not affect nicotine withdrawal-induced changes in attention and impulsivity in normal subjects (Ray et al., 2009), it may alleviate the withdrawal symptoms that make smoking cessation more difficult in patients with ADHD; this requires testing. Of interest, other disorders associated with smoking and deficits in impulse control may receive therapeutic benefits from reducing impulsivity. In addition to its established efficacy in the treatment of ADHD symptoms (Kratochvil et al., 2003), atomoxetine has also been suggested as a potential treatment for subjects with schizophrenia who smoke cigarettes (Sacco et al., 2009). Treatment of nicotine addiction along with disorders that present with impulsive symptoms is not straightforward, but may lead to better outcomes and quality of life.

The ability of acute nicotine to increase efficiency in cognitive tasks could contribute to initial use of tobacco products, but the mechanisms responsible for these changes in efficiency are not completely clear. Multiple factors could influence performance efficiency in the appetitive signaled nose-poke task. Although it is difficult to tease apart these factors, they include effects on impulse control, changes in the perception of time, and changes in the incentive salience of the conditioned reward. Previous work that used this task proposed 
that changes in impulsivity could alter efficiency (Logue et al., 1998; Bowers \& Wehner, 2001; Keller et al., 2005; Krueger et al., 2006). Thus, in the current study, the decreased premature responding and increased efficiency could be due to decreased impulsivity, but impulsivity is complex and multifactorial (as reviewed by Evenden, 1999; Mitchell, 2004) and studies would have to specifically examine these factors. An alternative explanation is that changes in efficiency were due to changes in the ability to properly time responses. It has been suggested that nicotine can affect the timing of responding (Meck, 2007). This possibility would also require further examination. Another possible interpretation is that nicotine is modulating the incentive salience of motivated responding (Berridge, 2009, 2012), thereby decreasing unnecessary responses. A change in incentive could lead to an increase or decrease in rewards earned, which was not seen in the present study.

In summary, the present study suggests that nicotine may initially have positive effects on processes that can influence response inhibition, but these effects may dissipate with continued nicotine admission. Thus, individuals with impulse control issues, such as patients with ADHD, schizophrenia, bipolar disorder, and PTSD, may begin smoking as a form of self-medication. However, tolerance may develop to the effects of nicotine on inhibitory control and the individual may be no better off as far as symptomology. Further, these individuals may be worse off in terms of the development of a nicotine addiction and may be more sensitive to withdrawal-related effects (Pomerleau et al., 2003; McClernon et al., 2011). It is also interesting to note that although we have found strong effects of nicotine withdrawal on cognitive tasks involving contextual learning (Davis et al., 2005), spatial learning (Kenney et al., 2011), and working memory (Raybuck \& Gould, 2009), the lack of withdrawal effects in the current study suggest that nicotine withdrawal has selective effects on cognitive processes.

\section{Supplementary Material}

Refer to Web version on PubMed Central for supplementary material.

\section{Acknowledgments}

This work was funded with grant support from the National Institute on Drug Abuse (DA017949 to Thomas J. Gould) and the National Cancer Institute (Caryn Lerman, CA143187). Prescott T. Leach was supported by National Institutes of Health-National Institute on Drug Abuse training grant DA07237.

\section{References}

Banks MK, Besheer J, Szypczak J, Goodpaster LL, Phipps EJ, Garraghty PE. The effects of carbamazepine on an appetitiveto-aversive transfer task: Comparison to untreated and phenytoin. Progress in Neuro-Psychopharmacology and Biological Psychiatry. 2001; 25:551-572. doi:10.1016/ S0278-5846(00)00175-5. [PubMed: 11370997]

Banks MK, Mohr NL, Besheer J, Steinmetz JE, Garraghty PE. The effects of phenytoin on instrumental appetitive-to-aversive transfer in rats. Pharmacology, Biochemistry and Behavior. 1999; 63:465-472. doi:10.1016/S0091-3057(99)00019-2.

Barker, P.; Bose, J.; Gfroerer, J.; Han, B.; Hedden, SL.; Hughes, A.; Tice, P. Results from the 2009 National Survey on Drug Use and Health: Volume I. Summary of national findings. Department of Health and Human Services Office of Audit Services; Washington, DC: 2010. [HHS Publication] 
Berridge KC. 'Liking' and 'wanting' food rewards: Brain substrates and roles in eating disorders. Physiology \& Behavior. 2009; 97:537-550. doi:10.1016/j.physbeh.2009.02.044. [PubMed: 19336238]

Berridge KC. From prediction error to incentive salience: Mesolimbic computation of reward motivation. European Journal of Neuroscience. 2012; 35:1124-1143. doi:10.1111/j. 1460-9568.2012.07990.x. [PubMed: 22487042]

Bowers BJ, Wehner JM. Ethanol consumption and behavioral impulsivity are increased in protein kinase Cgamma null mutant mice. The Journal of Neuroscience. 2001; 21:180.

Callinan JE, Clarke A, Doherty K, Kelleher C. Legislative smoking bans for reducing secondhand smoke exposure, smoking prevalence and tobacco consumption. Cochrane Database Systematic Reviews. 2010 CD005992.

Covey LS, Manubay J, Jiang H, Nortick M, Palumbo D. Smoking cessation and inattention or hyperactivity/impulsivity: A post hoc analysis. Nicotine \& Tobacco Research. 2008; 10:1717-1725. doi:10.1080/14622200802443536. [PubMed: 19023824]

Davis JA, Gould TJ. Atomoxetine reverses nicotine withdrawal-associated deficits in contextual fear conditioning. Neuropsychopharmacology. 2007; 32:2011-2019. doi:10.1038/sj.npp.1301315. [PubMed: 17228337]

Davis JA, James JR, Siegel SJ, Gould TJ. Withdrawal from chronic nicotine administration impairs contextual fear conditioning in C57BL/6 mice. The Journal of Neuroscience. 2005; 25:8708-8713. doi:10.1523/JNEUROSCI.2853-05.2005. [PubMed: 16177040]

Day M, Pan JB, Buckley MJ, Cronin E, Hollingsworth PR, Hirst WD, Fox GB. Differential effects of ciproxifan and nicotine on impulsivity and attention measures in the 5-choice serial reaction time test. Biochemical Pharmacology. 2007; 73:1123-1134. doi:10.1016/j.bcp.2006.12.004. [PubMed: 17214974]

De Biasi M, Dani JA. Reward, addiction, withdrawal to nicotine. Annual Review of Neuroscience. 2011; 34:105-130. doi:10.1146/ annurev-neuro-061010-113734.

Elkins IJ, McGue M, Iacono WG. Prospective effects of attention-deficit/hyperactivity disorder, conduct disorder, and sex on adolescent substance use and abuse. Archives of General Psychiatry. 2007; 64:1145-1152. doi:10.1001/archpsyc.64.10.1145. [PubMed: 17909126]

Evenden JL. Varieties of impulsivity. Psychopharmacology. (Berl). 1999; 146:348-361. doi:10.1007/ PL00005481. [PubMed: 10550486]

Finn PR, Justus A, Mazas C, Steinmetz JE. Working memory, executive processes and the effects of alcohol on Go/No-Go learning: Testing a model of behavioral regulation and impulsivity. Psychopharmacology (Berl). 1999; 146:465-472. doi:10.1007/PL00005492. [PubMed: 10550497]

Fuemmeler BF, Kollins SH, McClernon FJ. Attention deficit hyperactivity disorder symptoms predict nicotine dependence and progression to regular smoking from adolescence to young adulthood. Journal of Pediatric Psychology. 2007; 32:1203-1213. doi:10.1093/jpepsy/jsm051. [PubMed: 17602186]

Glynn DA, Cryan JF, Kent P, Flynn RA, Kennedy MP. Update on smoking cessation therapies. Advances in Therapy. 2009; 26:369-382. doi:10.1007/s12325-009-0022-9. [PubMed: 19399385]

Grottick AJ, Higgins GA. Effect of subtype selective nicotinic compounds on attention as assessed by the five-choice serial reaction time task. Behavioural Brain Research. 2000; 117:197-208. doi: 10.1016/S0166-4328(00)00305-3. [PubMed: 11099773]

Hahn B, Sharples CG, Wonnacott S, Shoaib M, Stolerman IP. Attentional effects of nicotinic agonists in rats. Neuropharmacology. 2003; 44:1054-1067. doi:10.1016/S0028-3908(03)00099-6. [PubMed: 12763099]

Hahn B, Shoaib M, Stolerman IP. Nicotine-induced enhancement of attention in the five-choice serial reaction time task: The influence of task demands. Psychopharmacology (Berl). 2002a; 162:129_ 137. doi:10.1007/s00213-002-1005-6. [PubMed: 12110990]

Hahn B, Shoaib M, Stolerman IP. Effects of dopamine receptor antagonists on nicotine-induced attentional enhancement. Behavioural Pharmacology. 2002b; 13:621-632. doi: 10.1097/00008877-200212000-00003. [PubMed: 12478212] 
Henningfield JE, Goldberg SR. Nicotine as a reinforcer in human subjects and laboratory animals. Pharmacology, Biochemistry and Behavior. 1983; 19:989-992. doi: 10.1016/0091-3057(83)90405-7.

Huddy VC, Aron AR, Harrison M, Barnes TR, Robbins TW, Joyce EM. Impaired conscious and preserved unconscious inhibitory processing in recent onset schizophrenia. Psychological Medicine. 2009; 39:907-916. doi:10.1017/S0033291708004340. [PubMed: 18796175]

Humfleet GL, Prochaska JJ, Mengis M, Cullen J, Munoz R, Reus V, Hall SM. Preliminary evidence of the association between the history of childhood attention-deficit/hyperactivity disorder and smoking treatment failure. Nicotine \& Tobacco Research. 2005; 7:453-460. doi: 10.1080/14622200500125310. [PubMed: 16085513]

Keller JJ, Keller AB, Bowers BJ, Wehner JM. Performance of alpha7 nicotinic receptor null mutants is impaired in appetitive learning measured in a signaled nose poke task. Behavioural Brain Research. 2005; 162:143-152. doi:10.1016/j.bbr.2005.03.004. [PubMed: 15922075]

Kenney JW, Adoff MD, Wilkinson DS, Gould TJ. The effects of acute, chronic, and withdrawal from chronic nicotine on novel and spatial object recognition in male C57BL/6J mice. Psychopharmacology (Berl). 2011; 217:353-365. [PubMed: 21487656]

Kratochvil CJ, Vaughan BS, Harrington MJ, Burke WJ. Atomoxetine: A selective noradrenaline reuptake inhibitor for the treatment of attention-deficit/hyperactivity disorder. Expert Opinions in Pharmacotherapy. 2003; 4:1165-1174. doi:10.1517/14656566.4.7.1165.

Krueger DD, Howell JL, Hebert BF, Olausson P, Taylor JR, Nairn AC. Assessment of cognitive function in the heterozygous reeler mouse. Psychopharmacology (Berl). 2006; 189:95-104. doi: 10.1007/s00213-006-0530-0. [PubMed: 16977475]

Le Foll B, Goldberg SR. Effects of nicotine in experimental animals and humans: An update on addictive properties. Handbook of Experimental Pharmacology. 2009; 192:335-367. [PubMed: 19184655]

Leonard S, Adler LE, Benhammou K, Berger R, Breese CR, Drebing C, Freedman R. Smoking and mental illness. Pharmacology, Biochemistry and Behavior. 2001; 70:561-570. doi:10.1016/ S0091-3057(01)00677-3.

Logue SF, Swartz RJ, Wehner JM. Genetic correlation between performance on an appetitive-signaled nosepoke task and voluntary ethanol consumption. Alcoholism: Clinical and Experimental Research. 1998; 22:1912-1920. doi:10.1111/j.1530-0277.1998.tb05898.x.

McClernon FJ, Van Voorhees EE, English J, Hallyburton M, Holdaway A, Kollins SH. Smoking withdrawal symptoms are more severe among smokers with ADHD and independent of ADHD symptom change: Results from a 12-day contingency-managed abstinence trial. Nicotine \& Tobacco Research. 2011; 13:784-792. doi:10.1093/ntr/ntr073. [PubMed: 21571687]

Meck WH. Acute ethanol potentiates the clock-speed enhancing effects of nicotine on timing and temporal memory. Alcoholism: Clinical and Experimental Research. 2007; 31:2106-2113. doi: 10.1111/j.1530-0277.2007.00540.x.

Milberger S, Biederman J, Faraone SV, Chen L, Jones J. ADHD is associated with early initiation of cigarette smoking in children and adolescents. Journal of the American Academy of Child and Adolescent Psychiatry. 1997; 36:37-44. doi:10.1097/00004583-199701000-00015. [PubMed: 9000779]

Mitchell SH. Measuring impulsivity and modeling its association with cigarette smoking. Behavioral and Cognitive Neuroscience Reviews. 2004; 3:261-275. doi:10.1177/1534582305276838. [PubMed: 15812110]

Navarra R, Graf R, Huang Y, Logue S, Comery T, Hughes Z, Day M. Effects of atomoxetine and methylphenidate on attention and impulsivity in the 5-choice serial reaction time test. Progress in Neuro-Psychopharmacology \& Biological Psychiatry. 2008; 32:34-41. doi:10.1016/j.pnpbp. 2007.06.017. [PubMed: 17714843]

Ockene IS, Miller NH. Cigarette smoking, cardiovascular disease, and stroke: A statement for healthcare professionals from the American Heart Association. American Heart Association Task Force on Risk Reduction. Circulation. 1997; 96:3243-3247. doi:10.1161/01.CIR.96.9.3243. [PubMed: 9386200] 
Pattij T, Janssen MC, Loos M, Smit AB, Schoffelmeer AN, van Gaalen MM. Strain specificity and cholinergic modulation of visuospatial attention in three inbred mouse strains. Genes Brain \& Behavior. 2007; 6:579-587. doi:10.1111/j.1601-183X.2006.00284.x.

Pomerleau CS, Downey KK, Snedecor SM, Mehringer AM, Marks JL, Pomerleau OF. Smoking patterns and abstinence effects in smokers with no ADHD, childhood ADHD, and adult ADHD symptomatology. Addictive Behaviors. 2003; 28:1149-1157. doi:10.1016/S0306-4603(02)00223X. [PubMed: 12834657]

Pomerleau OF, Downey KK, Stelson FW, Pomerleau CS. Cigarette smoking in adult patients diagnosed with attention deficit hyperactivity disorder. Journal of Substance Abuse. 1995; 7:373378. doi:10.1016/0899-3289(95)90030-6. [PubMed: 8749796]

Potter AS, Newhouse PA. Effects of acute nicotine administration on behavioral inhibition in adolescents with attention-deficit/ hyperactivity disorder. Psychopharmacology (Berl). 2004; 176:182-194. doi:10.1007/s00213-004-1874-y. [PubMed: 15083253]

Ray R, Rukstalis M, Jepson C, Strasser A, Patterson F, Lynch K, Lerman C. Effects of atomoxetine on subjective and neurocognitive symptoms of nicotine abstinence. Journal of Psychopharmacology. 2009; 23:168-176. doi:10.1177/0269881108089580. [PubMed: 18515446]

Raybuck JD, Gould TJ. Nicotine withdrawal-induced deficits in trace fear conditioning in C57BL/6 mice-a role for high-affinity beta2 subunit-containing nicotinic acetylcholine receptors. European Journal of Neuroscience. 2009; 29:377-387. doi:10.1111/j.1460-9568.2008.06580.x. [PubMed: 19200240]

Rukstalis M, Jepson C, Patterson F, Lerman C. Increases in hyperactive-impulsive symptoms predict relapse among smokers in nicotine replacement therapy. Journal of Substance Abuse Treatment. 2005; 28:297-304. doi:10.1016/j.jsat.2005.02.002. [PubMed: 15925263]

Sacco KA, Creeden C, Reutenauer EL, Vessicchio JC, Weinberger AH, George TP. Effects of atomoxetine on cognitive function and cigarette smoking in schizophrenia. Schizophrenia Research. 2009; 107:332-333. doi:10.1016/j.schres.2008.09.026. [PubMed: 18995989]

Semenova S, Stolerman IP, Markou A. Chronic nicotine administration improves attention while nicotine withdrawal induces performance deficits in the 5-choice serial reaction time task in rats. Pharmacology, Biochemistry and Behavior. 2007; 87:360-368. doi:10.1016/j.pbb.2007.05.009.

Shoaib M, Bizarro L. Deficits in a sustained attention task following nicotine withdrawal in rats. Psychopharmacology (Berl). 2005; 178:211-222. doi:10.1007/s00213-004-2004-6. [PubMed: 15338107]

Steinmetz JE, Logue SF, Miller DP. Using signaled barpressing tasks to study the neural substrates of appetitive and aversive learning in rats: Behavioral manipulations and cerebellar lesions. Behavioral Neuroscience. 1993; 107:941-954. doi:10.1037/0735-7044.107.6.941. [PubMed: 8136069]

Strakowski SM, Fleck DE, DelBello MP, Adler CM, Shear PK, Kotwal R, Arndt S. Impulsivity across the course of bipolar disorder. Bipolar Disorders. 2010; 12:285-297. doi:10.1111/j. 1399-5618.2010.00806.x. [PubMed: 20565435]

Swan GE, Lessov-Schlaggar CN. The effects of tobacco smoke and nicotine on cognition and the brain. Neuropsychology Review. 2007; 17:259-273. doi:10.1007/s11065-007-9035-9. [PubMed: 17690985]

Vansickel AR, Stoops WW, Glaser PE, Poole MM, Rush CR. Methylphenidate increases cigarette smoking in participants with ADHD. Psychopharmacology (Berl). 2011; 218:381-390. doi: 10.1007/s00213-011-2328-y. [PubMed: 21590284]

Victor SE, Johnson SL, Gotlib IH. Quality of life and impulsivity in bipolar disorder. Bipolar Disorders. 2011; 13:303-309. doi:10.1111/j.1399-5618.2011.00919.x. [PubMed: 21676133]

Weiss NH, Tull MT, Viana AG, Anestis MD, Gratz KL. Impulsive behaviors as an emotion regulation strategy: Examining associations between PTSD, emotion dysregulation, and impulsive behaviors among substance dependent inpatients. Journal of Anxiety Disorders. 2012; 26:453-458. doi: 10.1016/j.janxdis.2012.01.007. [PubMed: 22366447]

Wilens TE, Adamson J, Monuteaux MC, Faraone SV, Schillinger M, Westerberg D, Biederman J. Effect of prior stimulant treatment for attention-deficit/hyperactivity disorder on subsequent risk 
for cigarette smoking and alcohol and drug use disorders in adolescents. Archives De Pediatrie \& Adolescent Medicine. 2008; 162:916-921. doi:10.1001/archpedi.162.10.916.

Young JW, Finlayson K, Spratt C, Marston HM, Crawford N, Kelly JS, Sharkey J. Nicotine improves sustained attention in mice: Evidence for involvement of the alpha7 nicotinic acetylcholine receptor. Neuropsychopharmacology. 2004; 29:891-900. doi:10.1038/sj.npp.1300393. [PubMed: 14970827] 


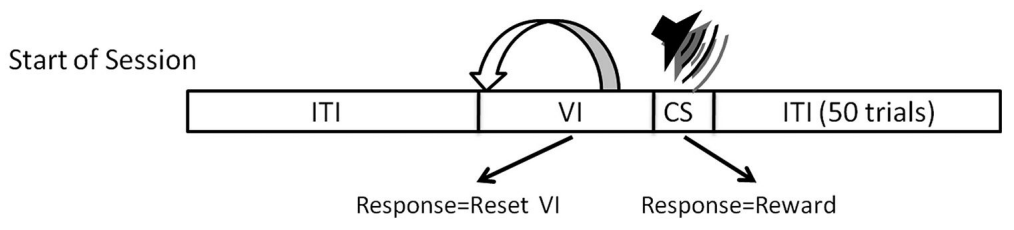

Figure 1.

Schematic of Phases 3-5 of the appetitive signaled nose-poke task. ITI (20 or $30 \mathrm{~s}$ ) is followed by a VI (1-8 s) during which premature responses restart the interval. Following successful response inhibition, CS ( 2 or 3 s) signals availability of nose poke for reward. 


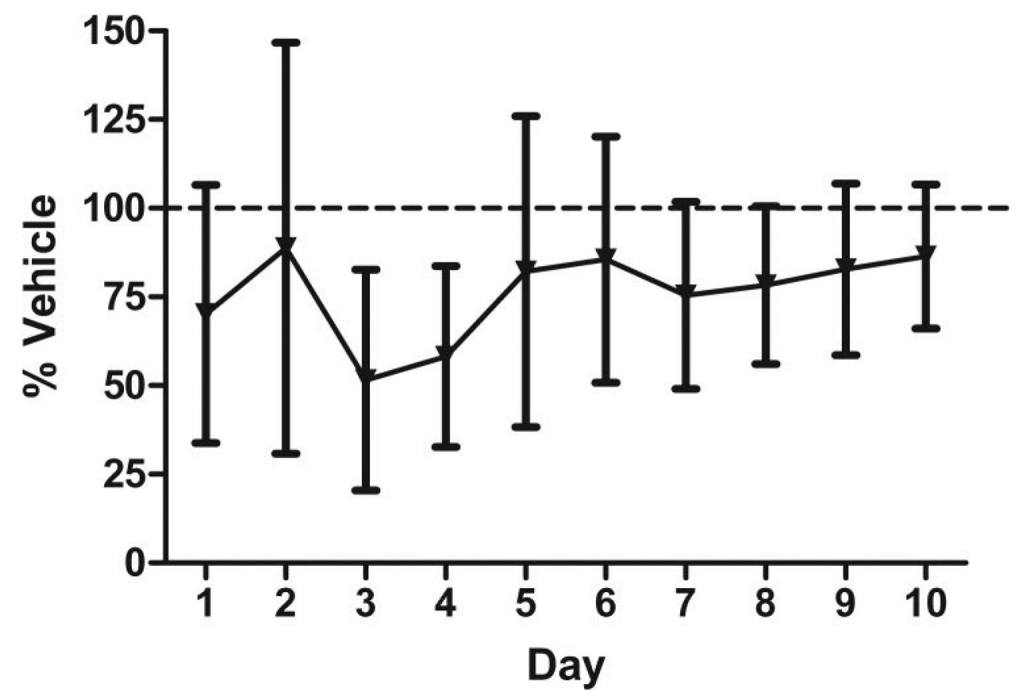

Figure 2.

Evaluation of the effect of acute nicotine $(0.09 \mathrm{mg} / \mathrm{kg})$ on acquisition of an operant task. Data points represent performance (ER) as a percent of vehicle-treated group over 10 days of acute drug administration and testing. Error bars represent \pm the standard error of the mean. 


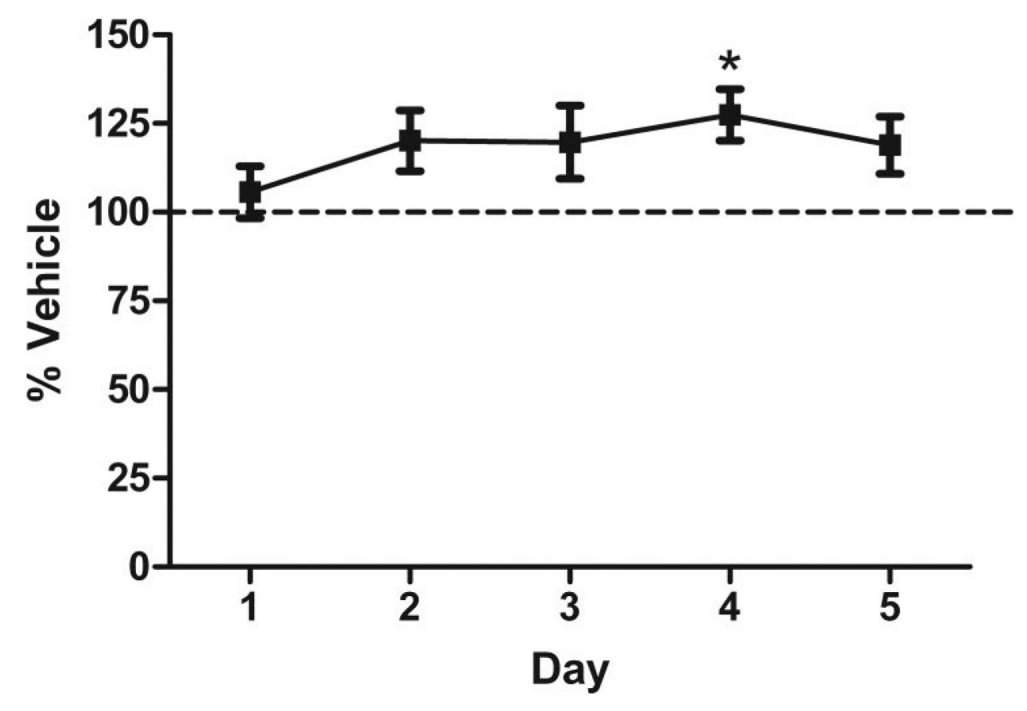

Figure 3.

Evaluation of the effect of acute nicotine $(0.09 \mathrm{mg} / \mathrm{kg})$ on performance efficiency. Data points represent performance (ER) as a percent of vehicle treated group over 5 days of acute drug administration and testing. Error bars represent \pm the standard error of the mean. * indicates significantly different from vehicle treated $(p<.05)$. 


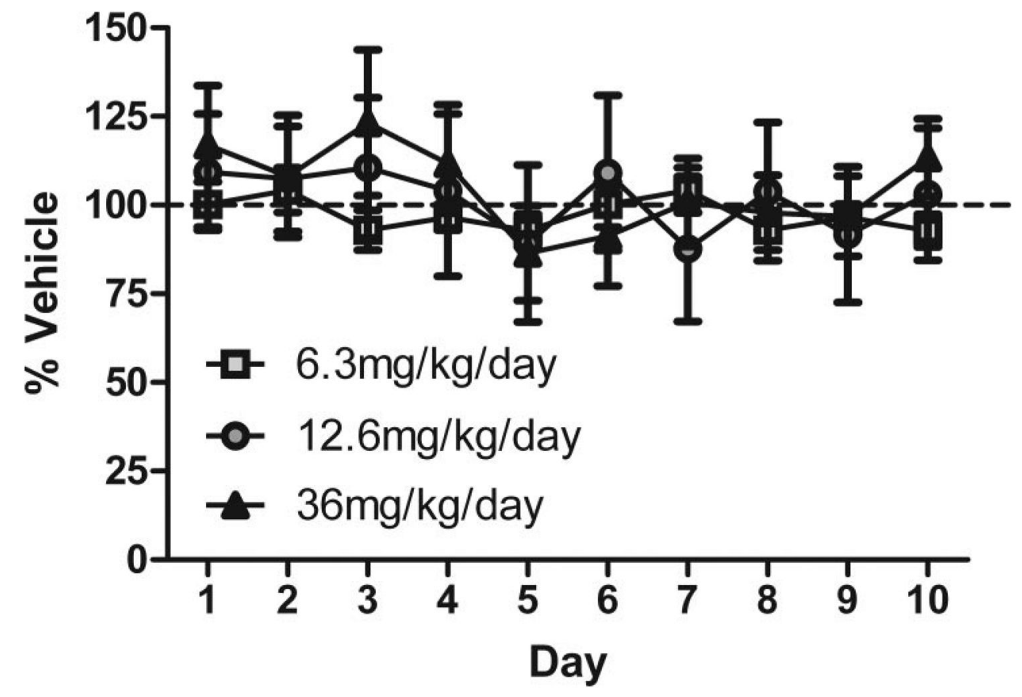

Figure 4.

Evaluation of the effect of chronic nicotine $(6.3,12.6$, or $36 \mathrm{mg} / \mathrm{kg} / \mathrm{day})$ on performance efficiency. Data points represent performance (ER) as a percent of respective vehicle treated group over 10 days of chronic drug administration and testing. Error bars represent \pm the standard error of the mean. 


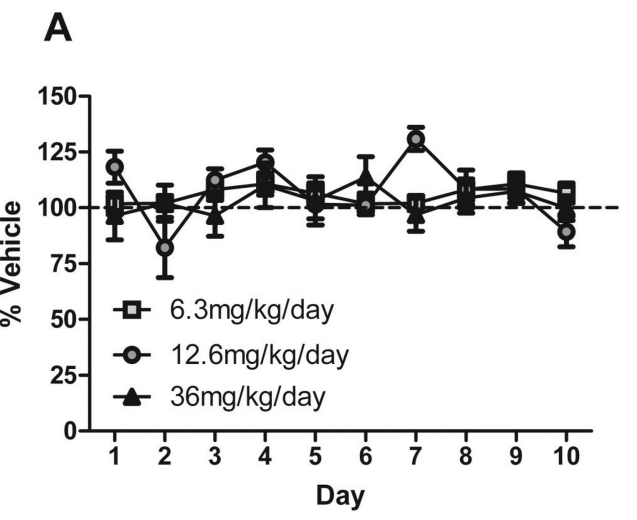

B

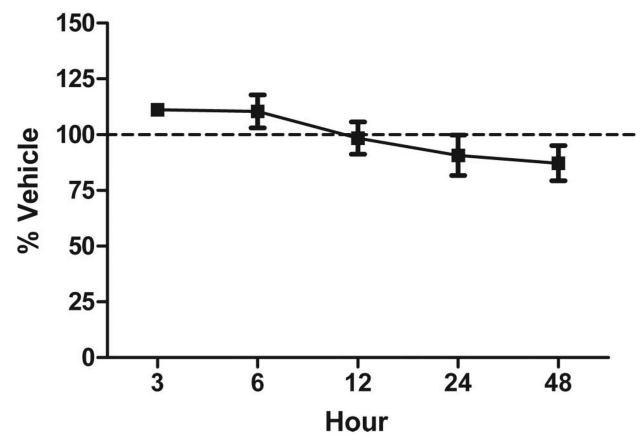

Figure 5.

Evaluation of the effect of withdrawal from chronic nicotine on performance efficiency. Data points represent performance (ER) as a percent of respective vehicle-treated group. Error bars represent \pm the standard error of the mean. Figure 5a shows the effect of withdrawal from chronic nicotine $(6.3,12.6$, or $36 \mathrm{mg} / \mathrm{kg} /$ day sc) commencing $24 \mathrm{hr}$ after spontaneous withdrawal. Figure $5 \mathrm{~b}$ shows the effect of withdrawal from chronic nicotine $(6.3 \mathrm{mg} / \mathrm{kg} /$ day sc) over the course of $48 \mathrm{hr}$ (tested at 3, 6, 12, 24, and $48 \mathrm{hr}$ after osmotic minipump removal). 